\title{
INVESTIGATION OF THE ENERGY POVERTY RISK WITH BUILDING MECHATRONICS
}

\author{
Péter T. Szemes \\ Dep. of Electrical Engineering and Mechatronics \\ University of Debrecen \\ Debrecen, Hungary \\ szemespeter@eng.unideb.hu
}

\author{
Nóra Tóth \\ Dep. of Electrical Engineering and Mechatronics \\ University of Debrecen \\ Debrecen, Hungary \\ tothnora@eng.unideb.hu
}

\begin{abstract}
Nowadays, the problem of energy poverty is a more and more frequent occurrence and its solution is a serious and urgent task. Energy poverty is closely related to the poor energy performance of residential stocks. Energy poverty is simultaneously an energetic and social question, due to involving households having bad energetic parameters. Because of bad efficiency, the energy costs are high related to earnings. It is not able to enhance the energy efficiency of buildings. Financial supports for endangered layers should contain measures to increase energy efficiency and decrease energy consumption. However, the concept of energy poverty is applied to social groups, like families or communities. In this paper, we extended the concept of energy poverty to SME (small and medium-sized enterprises). The paper introduces the concept and the risk of energy poverty and the technology of measuring those risks.
\end{abstract}

Keywords - energy; energy efficiency; energy poverty.

\section{INTRODUCTION}

The sociological approach of energy efficiency (energy poverty) is the new research direction of the Building Mechatronic Research Centre University of Debrecen Faculty of Engineering. The aim of this new research direction is to answer the European Union principle, which states that energy efficiency is not only an engineering problem but a social one as well. Our Research Centre came to existence in the frame of HURO-0901/028/ 2.3.1. E-Laboratory Practical Teaching for Applied Engineering Sciences project and the HURO/0802/155_Af Romanian -Hungarian R\&D Platform for Intelligent Building Research Projects Support project. These projects serve the transborder engineering and social development. This article is an introductory paper where we feature the sociological aspect of energy poverty risk connected to energy efficiency problem and engineering solutions. The examined places are households and SMEs. The importance of SMEs is significant because small and medium-sized enterprises are often referred to as the backbone of the European economy, providing a potential source for jobs and economic growth. One of the authors is a social politician and the other researcher is interested in robotics and building automation.

The paper is organized as follows: Section II is about the Importance of energy efficiency investments. Section III presents Definition of energy poverty. Section IV describes the
Measurement of energy poverty. Section V includes the summary.

\section{IMPORTANCE OF ENERGY EFFICIENCY INVESTMENTS}

All over the world, economy is based on fossil fuels (coal, petroleum, gas) which are decreased step by step. According to calculations, the coal and petroleum stocks are running out and they can assure the energy necessity of the world till around 60-80 years. Because of that and the climate changes, the political decision makers draw and start aims and programs, which are going to utilize renewable energies (wind energy, water energy, solar energy, biomass, geothermal energy), efficient utilization and saving of energy. The following table shows the energy dependency of the EU member states.

Fig. 1. EU27 Member State net (Extra-EU27) imports of natural gas, oil and solid fuels as a \% of total Gross Inland Energy Consumption, 2009

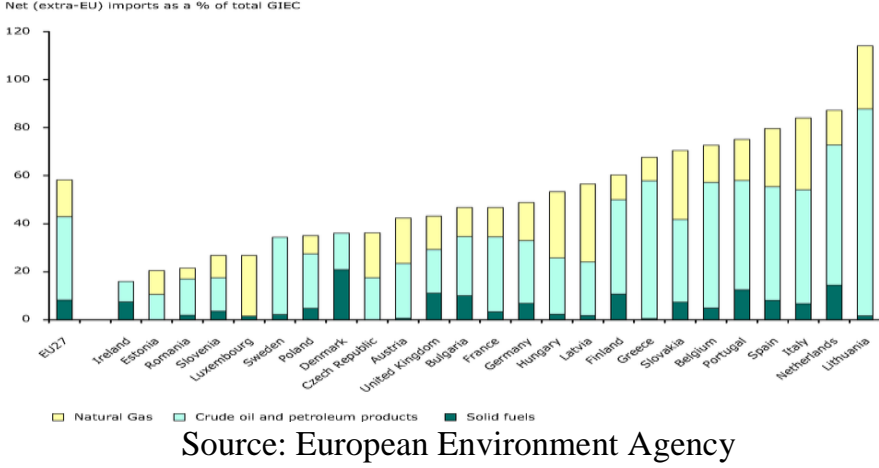

Currently, the central piece of the Union's climate policy is the EU Climate Change and Energy Package - the so-called 20-20-20 targets - which has added the goal of a $20 \%$ reduction in primary energy use to be achieved by improving energy efficiency to the two existing targets of reducing greenhouse gases previously to $20 \%$ and increasing the share of renewables to $20 \%$ of the EU's energy consumption by 2020 [16]. Reducing effect of energy crisis has got numerous possibilities on the level of national and local government.

Possibilities of the national interference: (1) increase the 
energy efficiency, create the background of law of new energy sources and form incentive system, (2) correction of the energy supply, supply researches focused on new more effective energy utilization, (3) development of energy efficient means of productions, buildings, (4) review of the new knowledge related to energy efficiency with people.

Possibilities of the local government: (1) organization of immigration of the enterprises concern with energy efficiency, (2) correction of the energy self-supply of the settlements, organization of the autonomous supply [1]. The cost of increased energy consumption, the depletion of fossil fuel reserves and the effect of human activities on global climate change are drivers of recent energy efficiency policies. Since 2000, the European Union, through its Cohesion Policy funds, spent almost $€ 5$ billion for co-financing energy efficiency measures in the Member States. The European Commission and the Member States are both responsible for the sound financial management of these funds [22]. The main break-up possibility from the economic crisis is making the energy consumption more efficient. The main financial priority will be the energy efficiency in the budgetary period of EU. Low energy efficiency could slow down the recovering from the economic crisis. It could be corrected with the least cost possible and the biggest climate and social protection benefits by the energy saving, sustainable renovation of the buildings [2]. The importance of these energy efficiency investments is significant in the liquidation of energy poverty. Otherwise decreasing of overheads was set on 01.01.2013 in Hungary. In course of it, the price of public gas, electricity and district heating was decreased with $10 \%$ and it can prevent the spread of the energy efficiency investments. The lower overhead price urge for wasting consumption and postponement of saving investments. Concept determined by economics is that the low price urgent the consumption so the overheads decreasing do not reduce the utilization and nor correct the energy efficiency. According to the measurement of the Hungarian Energy Efficiency Institute, $40 \%$ of the designer of energetic renovation would start renovation to decrease the overheads [3]. All governmental intervention has got social effects. The energy consumption habits of households and SMEs could be changed. It needs to be measured because the changed energy consumption habits influence the energy poverty risk. The overhead decrease has negative influence for SMEs too, because they have to pay the overhead decrease. Furthermore, suppliers rise the prices for SMEs. SMEs are defined by the European Commission as having less than 250 persons employed [25]. In every EU countries, the handling of energy poverty contains measures (renovation, support of modernization, information, shaping attitude) to increase energy efficiency and decrease energy consumption, to try to prevent the development of energy poverty [4].

Contrarily of these problems, in the European Union the Smart Grid is urged to spread this new energy efficiency program. Smart Grids enable consumers to control and manage their own energy use and therefore contribute towards establishing a power system that generates less carbon. The European Commission proposes to use these grids to their full capacity in order to achieve its objectives of reducing primary energy consumption [24]. According to the European Bio Intelligence study, the use of these grids could: (1) reduce the annual primary energy consumption of the EU energy sector by almost $9 \%$ by 2020, (2) create new jobs, (3) generate additional economic growth [23]. This new system has not been found in Hungary yet. However, if the energy efficiency of building stock is improved, the greenhouse gas emissions can be reduced significantly. It can also advance several social, political and economic policy agendas, including the improvement of energy security, social welfare, reduction of energy poverty, new business opportunities, market values of real estate, as well as improved air, life and health quality. Unfortunately, the inefficiency of building stocks is very high in Hungary. Hungary ranks among the top-ten EU27 countries in terms of specific dwelling energy consumption scaled to EU average climate [14].

Fig. 2. Households' specific energy consumption (kWh m-2 year-1) scaled to EU average climate. Hungary vs. CEE Member States. Average 2000-2007.

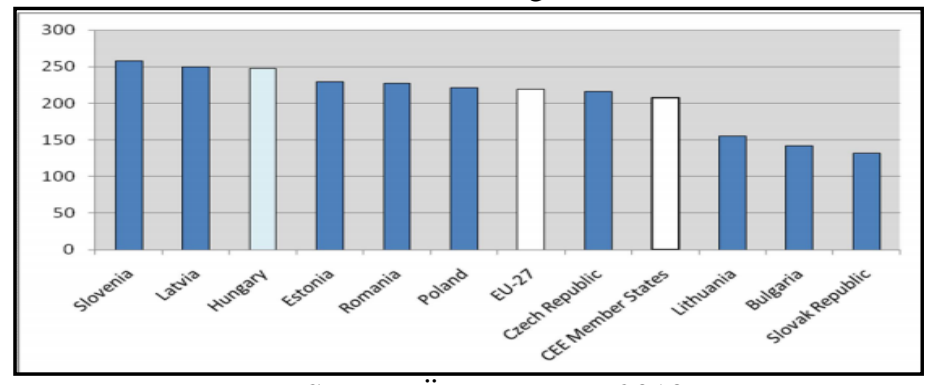

Source: Ürge-Vorsatz 2010

Improvements for energy efficiency contribute to tackle two challenges (energy dependency and energy poverty). It is simply enhancing the energy intensity reduction trend recorded for the Hungarian economy since the early 1990s. Currently, Hungary displays one of the lowest energy intensities among CEE Member States [14].

Fig. 3. Energy intensity of, EU-25, EU-15 (pre-2004 Members), EU-10 new Member States and selected CEE countries (2003). 


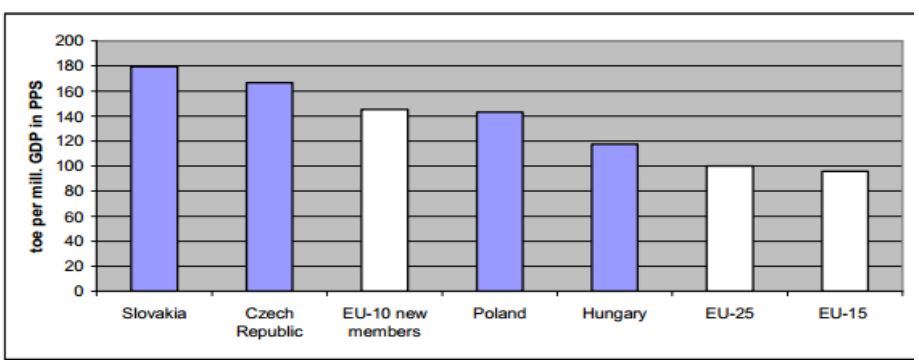

Source: Ürge-Vorsatz 2010

Eichhammer in the context of a European Commission project connected to the Directive 2006/32/EC on Energy End-use Efficiency and Energy Services found out that Hungary's energy saving potential in the middle-term (by 2020 and 2030) is greater than the EU27's average, and also that households are by far the sector with the largest potential in Hungary. But what do we mean by the concept of energy poverty?

Fig. 4. Energy saving potentials in 2030 for the main end-use sectors in Hungary

$\begin{array}{llll} & \text { Economic (LPI) } & \text { Economic (HPI) } & \text { Technical } \\ \text { Industry } & 7.2 \% & 8.3 \% & 11.9 \% \\ \text { Tertiary } & 16.1 \% & 29.3 \% & 38.8 \% \\ \text { Transport } & 12.3 \% & 20.6 \% & 26.4 \% \\ \text { Households } & 16.8 \% & 39.5 \% & 67.4 \%\end{array}$

Source: Eichhammer (2009)

\section{DEFINITION OF ENERGY POVERTY}

In the past few years, we heard more and more about energy poverty as an increasing problem having threatening results. The energy poverty firstly turned up in the 70 's- 80 as a serious social problem [5]. We talk about energy poverty when a person or a household is not able to heat his/her home on adequate level or cannot require energy services so he/she cannot satisfy his/her fundamental social and cultural necessity. Generally energy poverty is defined where more than $10 \%$ of the income has to be used for heating of the home [6]. Energy poverty has various definitions in the international literature. Common in them is that a household suffers energy poverty if it cannot heat its home for an adequate level and it spends more for energy bills than a definite percent of income. The adequate level of heating is determined as $21^{\circ} \mathrm{C}$ in living room and as $18^{\circ} \mathrm{C}$ in other places by the World Health Organization [28].Various as definition the amount of energy expenses and the defined percent above which the household is diagnosed energy poor. Using of the $10 \%$ ratio is widely spread, which was determined by Brenda Boardman in 1991 and the official United Kingdom's definition followed it. Later this ratio was called in question by a number of people [28]. Besides of that several definitions mention the content of households (elder, single, parents with children, etc.), standard of building (insulation standards, heating standards), position of building (urban, rural) and its utilization [7]. According to international literally, in the aspect of energy poverty the most endangered layers are the elders (especially the singles), the sick (especially people with long term diseases) and singles [8]. The reasons of energy poverty can be physical (especially respiratory) and mental (anxiety, feeling of isolation) diseases, drastic decay of building conditions involving increased $\mathrm{CO} 2$ emission and the grown debt of households [9]. The European Fuel Poverty and Energy Efficiency (EPEE) project examined the status of energy poverty in five European countries (United Kingdom, Spain, Italy, Belgium, and France). Nowadays, around 50-125 million people are concerned energy poor in Europe based on the project and this number will increase due to hard economic circumstances (financial and economic crisis, decrease in salary, increase in energy prices) in the near future [5]. The importance of energy poverty problem was firstly recovered in the United Kingdom. The objectives for 2010 (abolish the energy poverty among the protected households) in The UK Fuel Poverty Strategy published in 2001 was a failure that is why new objects for 2016 (total abolish of the energy poverty). In Hungary the research of the topic has been started in the past few years. The ENERGIAKLUB Climate Policy Institute Applied Communications made the first summary analysis about the Hungarian state support of public energy prices and it studied the handle of methods of energy poverty in the EU member states [10]. The energy poverty has not been regarded only a social question because it does not help to solve it. Energy poverty is simultaneously an energetic and a social question, since involving households having bad energetic parameters. Because of bad efficiency, the energy costs are high related to earnings. It is not able to enhance building energy efficiency. Besides its negative economic effect, it can cause serious medical problems (for example respiratory sickness, asthma, cardiovascular system complaints, hypertension, cancer) [14]. Following four factors are responsible for the development of energy poverty: (1) low earnings (even absolute poverty), (2) high prices of energy (possibly somebody is obliged to use expensive heating, for example using electrical current), (3) low energy efficiency of homes (bad isolation, out-of-date heating system), (4) low housing density (according to a research made in the United Kingdom, people suffering from the highest energy poverty lived lonely in a house bigger than an average house or in farm). Energy poverty appears in the context of poverty [11].

\section{MEASUREMENT OF ENERGY POVERTY}

By examining and monitoring a defined building, lowenergy efficiency is measured to turn out how much energy cost can be saved by households with an efficient building engineering and building mechatronic system. The proposal can be realized with examinations in the Building Mechatronics Research Centre. The building mechatronic 
examination is realized on three levels: (1) Orientation level: We use specific indicators using accounts, documents (for example ground plan), (2) Operational level: We achieve energy efficiency with changing of the operational habits. We measure energetic consumer habits and define the operational habits based on it, (3) Investment level: We achieve energy efficiency with the structural transformation of building engineering, - building automation system. In the Building Mechatronics Research Centre various energy efficiency scenarios can be examined [26].

Energy efficiency of households can be examined on all three levels. In technological viewpoint the first level is the most suitable one. If the orientation level is automated we will be able to filter the endangered groups with a fast test. The statistical methods screen the details by individually. There would be a need for a technological system, which can examine locally altogether the three levels. With the measure technologies of the Building Mechatronic Research Centre we can monitor and improve building energy performance according to the 2002/91/EC directive. The system includes a ZigBee based wireless sensor system, which is installed in the building to measure temperature, heat flow, boiler performance, gas and electricity consumption.

The obtained data is processed by a Decision Support System, which (1) calculates the current energy efficiency, (2) generates reconstruction plans and budget, and (3) calculates return of investment. The optimal (i.e. highest return of investment) reconstruction plan is selected and recommended to the user (decision maker). The optimization of reconstruction strategies (options among reconstruction plans) can be determined by setting the available budgets and other available resources such as renewable energies. The performance of the system was tested on a $3000 \mathrm{~m}^{2}$ school building complex, including of a 150-year-old and a 10 -yearold structure [26]. We use similar technology in the Building Mechatronic Research Centre.

The available, official Hungarian statistical data are not detailed enough to examine narrowly the problem of energy poverty. Although, the researches made in the NegaJoule2020 research project belongs to the ENERGIAKLUB Climate Policy Institute Applied Communications, contain detailed data referring to mapping the energetic features of domestic building substance and measuring the energy efficiency potential. Since their data registration contains questions referring to earning status of households, which gives possibility to examine the relation of energy costs and incomes. More than hundred completed energetic standard calculations insure information connection with the energy consumption of the different building types [5].

According to the survey based on the professed income and expense data, households found in parishes, in family houses, and in villages with bigger place are energy poor. Households with a single, pensioner or unemployed family member can be found with bigger ratio among the energy poverty households than in the full sample [5].

\section{A. Good practices for the energy efficiency}

The U.S. Department of Energy (DOE) Building Technologies Program has set goals of producing marketable net-zero energy buildings by 2025 . This goal will require collaboration between the DOE laboratories and the building industry. They developed standard or reference energy models for the most common commercial buildings to serve as starting points for energy efficiency research. These models represent fairly realistic buildings and typical construction practices. The reference building models cover 16 building types and 16 U.S. locations. Locations were selected to represent significant portions of the existing building stock and all U.S. climate zones [19]. The reference buildings provide a common starting point to measure the progress of DOE energy efficiency goals for commercial buildings. The models of the reference buildings are used for DOE commercial buildings research to assess new technologies; optimize designs; analyze advanced controls; develop energy codes and standards; and to conduct lighting, day lighting, ventilation, and indoor air quality studies. DOE's Building Energy Code Program and PNNL use these models for the analytical support in the development of new versions of ASHRAE Standard 90.1. [19].

We can find several good practices in the European Union, too. In England, from 1 April 2009 to 31 March 2010, the Warm Front project delivered energy efficiency improvements across a wide range of households. In the frame of this project poor households were given $100 \%$ support to heat insulation and modernization their heating by maximum 3500 pounds [20]. The FinSH (Financial and Support Instruments for Fuel Poverty in Social Housing) project examined the solutions of financial and other energy efficiency possibilities to decrease the energy poverty in just rented flats. During the period of the project (from December 2007 to May 2010), the aspect of energy poverty and the financial assets and laws were examined in five participant countries (France, United Kingdom, Italy, Germany, Poland) to observe how they could decrease the measure of energy poverty [21].

Sergio Tirado Herrero and Prof. Diana wrote down in their study the definition of the Hungarian measurement of the energy poverty. Based on this, they reviewed three approach levels of energy poverty (temperature, expenditure, consensual) and the quantitative measurement opportunities of energy poverty (Energy prices and households' income sources, the energy performance of the residential stock, measures based on the expenditure approach, measures based on the consensual approach, the health impact of fuel poverty: excess winter mortality (EWM) and morbidity effects).

Hereinafter these measurement definitions are presented shortly:

Three main approaches have been identified: (1) Temperature: which aims the detected households unable to 
satisfy an adequate heating? It provides direct measurements but is fraught with practical difficulties [27], (2) Expenditure: a more common approach, which defines a household of energy poverty when energy expenses are above a certain percentage of net income, (3) Consensual: it attempts to capture the wider elements of energy poverty. It accounts for certain household's attributes or lack of items (i.e. absence of central heating or presence of damp) as indicators of fuel poverty, since these are necessities widely recognized by society.

\section{B. Quantitative measurements of energy poverty:}

\section{1) Energy prices and households' income sources}

The examination of study determined that the rate of the prices of energy sources and main incomes of households (wages, pensions) has not raised between 2000 and 2008, however the price of energy sources had grown at a higher rate [14].

\section{2) The energy performance of the residential stock}

Data retrieved from the ODYSSEE database indicate that Hungary is one of the top-ten EU27 countries in terms of dwelling energy consumption per $\mathrm{m}^{2}$ scaled to EU average climate. On average for 2000/07, Hungarian dwellings' consumption was an $11 \%$ higher than the EU27 average [14]. Figure 5 shows the energy efficiency tendency in the EU- 27 countries, in households. We can see the decreasing progress.

Fig. 5. Energy efficiency progress for households in the EU-27: household ODEX

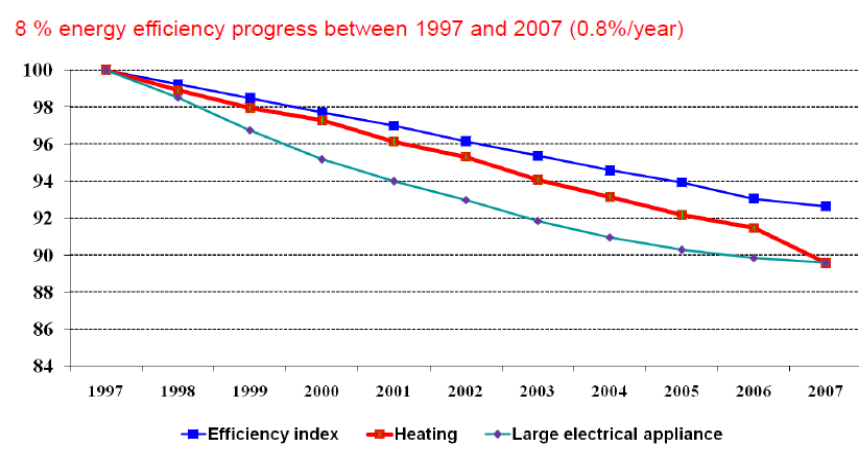

ODEX is an index weighting the energy efficiency progress gains of 8 end-uses/appliances : heating (toe/m2) WDEX is an index weighting the energy efficiency progress gains of 8 end-uses/appliances : heating (toe/m2)
water heating, cooking (toe/dwelling), refrigerators, freezers, washing machine, dishwashers and TV ( $\mathrm{kWh} / \mathrm{year}$ )

Source: Odyssee

According to the study, while the average Hungarian dwelling sector is among the most energy demanding of the EU, no significant improvement in its energy efficiency (rather the opposite) has happened since 2000. The reason of that is mainly the artificially low energy prices and subsidies for Hungarian households because they provide few incentives for investing in energy efficiency [13].

\section{3) Measures based on the expenditure approach}

According to the study we estimate the percentage of energy expenses in the households' income. If this combines with a threshold (i.e, $10 \%$ or more of the net income, as first proposed by Boardman, 1991) and a representative sample of households is available, then it is possible to estimate the number of households suffering from fuel poverty. The energy expenses of families have been around $10 \%(9.7 \%)$ of their net income between 2000 and 2007 [14].

The examinations of study determined that among energy carriers, electricity expenses were the highest among the various employed by the Hungarian domestic sector. Energy poverty hits harder the poorer members of society. By regions, the eastern part of the country (Northern Hungary, North Great Plain and South Great Plain) records the highest percentages of energy expenditures, reproducing the existing differences in regional economic performance. By household typologies, the category with the highest proportion of energy expenses vs. income $(14 \%)$ is the one-member household without children and, in general, households without children (11\%) perform worse than households with children $(9.6 \%)$. By age of the head of the household, the highest energy expenses vs. net income ratios (12\% and over) are recorded for households whose head is 65 years or older.

\section{4) Measures based on the consensual approach}

The consensual approach aims at accounting for certain basic goods (i.e. adequate heating facilities) or essential household attributes (i.e., a damp-free home) considered as 'socially perceived necessities' and whose absence can be taken as an indicator of energy poverty. Based on it we distinguish two subjective 'consensual' indicators (Inability to keep the home adequately warm, Arrears on utility bills) and one objective indicator (Leaking roof, damp walls, floors or foundation, or rot in window frames or floor).

\section{5) The health impact of fuel poverty: excess winter mortality and morbidity effects}

In Hungary between 1995 and 2007 an average of 5,566 more people died in winter (i.e., December to March) that in non-winter (i.e., August to November and April to July) season. The most excess winter deaths are registered for population over 40 years old (mostly among elders above 60) and are caused by diseases of the respiratory and circulatory system.

\section{CONCLUSION}

The paper proposed a new technological background in order to provide technological platform. The system is able to 
investigate the risks of energy poverty. Energy poverty is a hardly researched problem in Hungary and Europe in point of sociological view. Further researches are needed to define and measure the definition. This problem is not only a social but also an energy political question, because the reasons of energy efficiency are neglected. Although, the government led the $10 \%$ decrease of overheads in, these measures are just temporary solutions and campaign tools, too because the lower overhead price urge for wasting consumption and postponement of saving investments. Concept determined by economics is that low price urgent the consumption. The overheads decreasing do not decrease the utilization and nor correct energy efficiency.

Since the main cause of the energy poverty is the lowenergy efficient buildings, it is worth examining and monitoring a defined building to measure the low-energy to turn out how many energy cost can be saved by households with efficient building engineering and building mechatronic system.

\section{Acknowledgement}

The work is supported by the TÁMOP-4.2.2.A$11 / 1 / \mathrm{KONV}-2012-0041$ project. The project is co-financed by the European Union and the European Social Fund.

\section{References}

[1] J. Tamás, L. Blaskó, "Curriculum development to prepare for economic function in MSc level - environment technology in scope of knowledge", University of Debrecen, Centre for Agricultural and Applied Economic 2011. http://www.tankonyvtar.hu/hu/tartalom/tamop425/0032_kornyezettechn ologia/0032_kornyezettechnologia.docx

[2] New Széchenyi Plan, "Green economic development program", 2011. pp. 131. http://ujszechenyiterv.gov.hu/lapozo/zoldgazdasag

[3] B. Nagy, "The public utility account should be the escort of free credit in the future",

2013. http://www.penzcentrum.hu/energia/a_kozmuszamla_lehet_a_jovo_ingy enhitelenek_fedezete.1035247.html?utm_source=index_main\&utm_med ium=portfolio_box\&utm_campaign=portfoliobox

[4] D. Fellegi, "Examination and proposals in the topic of the state support of the energy poverty and the energy prices",Energyclub, Budapest, 2010 .,

http://energiaklub.hu/sites/default/files/energiaarak_v_energiaszegenyse g.pdf

[5] D. Fellegi, O. Fülöp, "Poverty or energy poverty? The definition of the energy poverty in Europe and in Hungary", Energyclub, Budapest, 2012..

http://energiaklub.hu/sites/default/files/energiaklub_szegenyseg_vagy_e nergiaszegenyseg.pdf

[6] D. Fellegi, „Energy poverty, general survey in the European Union”, Energyclub, Budapest, 2009 Helyzetkép az Európai Unióban. Budapest, 2009. http://energiaklub.hu/sites/default/files/fuel_poverty_tanulmany.pdf

[7] Fuel Poverty Explanatory Note. http://www.eastlothian.gov.uk/downloads/download/869/fuel_poverty_e xplanatory_note
[8] Tackling Fuel Poverty in Europe -Recommandations Guide for Policy Makers, „European Fuel Poverty and Energy Efficiency” -EPEE, 2009 http://www.fuel-poverty.org/files/WP5_D15_EN.pdf

[9] EUROPEAN FUEL POVERTY AND ENERGY EFFICIENCY,WP2D5 -Diagnosis of causes and consequences o fuel poverty in Belgium, France, Italy, Spain and United Kingdom http://www.fuelpoverty.org/files/WP2_D5_final.pdf

[10] D. Fellegi, O. Fülöp, "Poverty or energy poverty? What is the energy poverty? Energy poverty in the world and in Hungary", Energyclub, Budapest, 2011. http://www.vedegylet.hu/doc/energianyomda.pdf

[11] L. Koltai, "Hypothermia and Frost killing, Fast report", Habitat for Humanity, Budapest, 2013. http://www.habitat.hu/files/Habitat_kihules2013.pdf

[12] S. T.Herrero, D. Ürge-Vorsatz, "Fuel poverty in Hungary: a first assessment", Center for Climate Change and Sustainable Energy Policy at Central European University, 2010. http://3csep.ceu.hu/sites/default/files/field_attachment/project/node3347/englishreportfuelpoverty.pdf

[13] O. Fülöp,"Motivated wasting - State support of the residental energy prices 2003-2009", Energyclub, Budapest, 2009. http://energiaklub.hu/sites/default/files/energiaarak_allami_tamogatasa_ 0906.pdf

[14] Ürge-Vorsatz, D., Daniele Arena, S. T. Herrero, A. Butcher, Á. Telegdy, S. Fegyverneky, T. Csoknyai, É. Köpataki, A. Jankó, "Employment Impacts of a Large-Scale Deep Building Energy Retrofit Programme in Hungary", Central European University, Budapest, 2010. http://3csep.ceu.hu/sites/default/files/field_attachment/project/node6234/employment-impactsofenergyefficiencyretrofits.pdf

[15] Eichhammer, W., Fleiter, T., Schlomann, B., Faberi, S., Fioretto, M., Piccioni, N., Lechtenböhmer, S., Schüring, A. and Resch, G., "Study on the Energy Savings Potentials in EU Member States, Candidate Countries and EEA Countries. Final Report" Karlsruhe,Grenoble, Rome ,Vienna, 2009.2 Wuppertal. http://ec.europa.eu/energy/efficiency/studies/doc/2009_03_15_esd_effici ency_potentials_final_report.pdf

[16] Commission of the European Communities 2008. 2020 by 2020. Europe's climate change opportunity. Communication from the Commission to the European Parliament, the Council, the European Economic and Social Committee and the Committee of the Regions. $\operatorname{COM}(2008) \quad 30$ final. Brussels, 23.1.2008. http://eurlex.europa.eu/LexUriServ/LexUriServ.do?uri=COM:2008:0013:FIN:EN :pdf

[17] Odyssee - Energy Efficiency Indicators in Europe http://www.odysseeindicators.org/reports/household/household9.pdf

[18] European Environment Agency database http://www.eea.europa.eu/dataand-maps/figures/member-state-net-extra-eu27-2

[19] M. Deru, K. Field, D. Studer, K. Benne, B.Griffith, P. Torcellini, B. Liu, M. Halverson, D. Winiarski, M. Rosenberg, M. Yazdanian, J. Huang, D. Crawley, "U.S. Department of Energy commercial reference building models of the national building stock" National Renewable Energy Laboratory, Colorado, http://www.nrel.gov/docs/fy11osti/46861.pdf

[20] R. Armstrong, "The Warm Front Scheme Annual Report 2009/10.", 2010.

https://www.gov.uk/government/uploads/system/uploads/attachment_dat a/file/48034/1281-warm-front-annual-report-2009-10.pdf

[21] M.-A. Quadrio, "Financial and Support Instruments for Fuel Poverty in Social Housing (FINSH)", Intelligent Energy Europe, 2010. http://eaciprojects.eu/iee/page/Page.jsp?op=project_detail\&prid=1586

[22] European Court Of Auditors, "EU Energy Efficiency: investment targets not achieved; average pay back period exceeds 50 years (in extreme cases 150 years)" PRESS RELEASE, Luxembourg, 14 January 2013 http://europa.eu/rapid/press-release_ECA-12-55_en.htm

[23] A. Beton, C. D. Abbayes, S. Iyama, "European Comission DG INFSO. Impacts of Information and Communication Technologies on Energy Efficiency. Final Report", Bio Intelligent Service,2008 $\mathrm{ftp} / / / \mathrm{ftp}$.cordis.europa.eu/pub/fp7/ict/docs/sustainable-growth/ict4eefinal-report_en.pdf 
Recent Innovations in Mechatronics (RIiM) Vol. 1. (2014). No. 1-2.

DOI: $10.17667 /$ riim.2014.1-2/10.

[24] Commission Recommendation of 9 March 2012 on preparations for the roll-out of smart metering systems. http://eurlex.europa.eu/LexUriServ/LexUriServ.do?uri=OJ:L:2012:073:0009:01: EN:HTML

[25] Small and medium-sized enterprises. http://epp.eurostat.ec.europa.eu/statistics_explained/index.php/Small_an d_medium-sized_enterprises

[26] P. T. Szemes, Zs. Baranyai, J. Hamar, M. Zoltai, "Energymon": Development of Wireless Sensor Network Based Decision Support System to Monitor Building Energy Performance”, pp. 31-36. 2011 IEEE/ASME International Conference on Advanced Intelligent Mechatronics (AIM 2011) Budapest, 3 - 7 July 2011

[27] Kalmár T; Husi G; Yildirim Ş; Kalmár F; Eski I, „Neural network predictor for thermal comfort conditions, JOURNAL OF COMPUTER SCIENCE AND CONTROL SYSTEMS", ISSN: 18446043, 2: 2 pp. 97-102. 2009

[28] Kalmár F; Kalmár T; Csáki I; Husi G, "Interrelation between ACH and air temperature distribution in a room", ROOMVENT 2009: Proceedings of the 11th International ROOMVENT Conference. Busan, South-Corean, 2009.05.24-2009.05.29. 